\title{
Fotossensibilização primária em equiídeos e ruminantes no semi-árido causada por Froelichia humboldtiana (Amaranthaceae) ${ }^{1}$
}

\author{
Luciano A. Pimentel ${ }^{2}$, Franklin Riet-Correa ${ }^{3}$, Karla M.R. Guedes ${ }^{4}$, Juliana T.S.A. \\ Macêdo $^{4}$, Rosane M.T. Medeiros ${ }^{3}$ e Antônio F.M. Dantas ${ }^{3}$
}

\begin{abstract}
Pimentel L.A., Riet-Correa F., Guedes K.M., Macêdo J.T.S.A., Medeiros R.M.T. \& Dantas A.F.M. 2007. [Primary photosensitization in equidae and ruminants in the Brazilian semi-arid caused by Froelichia humboldtiana (Amaranthaceae).] Fotossensibilização primária em equí́deos e ruminantes no semi-árido causada por Froelichia humboldtiana (Amaranthaceae). Pesquisa Veterinária Brasileira 27(1):23-28. Hospital Veterinário, CSTR, Universidade Federal de Campina Grande, Campus de Patos, Patos, PB 58708-110, Brazil. E-mail: franklin.riet@pesquisador.com.br

Photosensitization is common in the Brazilian semiarid, affecting mainly horses, but also donkeys, mules, sheep and cattle. The dermatitis affects mainly non pigmented skin, and the animals recover after being withdrawn from the pastures. To demonstrate the etiology of the disease, Froelichia humboldtiana (Roem. et Schult.) Seub., collected in the field one or two times a week and kept in the refrigerator for 1-4 days, was administered for 30 or more days as the only food ad libitum to 2 donkeys and one white sheep, and as the only forage ad libitum, to one white horse. No clinical signs were observed in those animals, and serum activities of aspartate-aminotransferase (AST), alanine-aminotransferase (AST), and gamma-glutamyltransferase (GGT) were within normal ranges. In another experiment, one sheep was tied by a rope, during the day, in a pasture of exclusively $F$. humboldtiana for a 26 days period. Skin lesions characteristic of photosensitization appeared 4-5 days after the start of the experiment and became severe until day 26 . After the withdrawal of the animal from the pasture on day 26 it fully recovered within 30 days. In another experiment, 4 sheep were tied by ropes in the same pasture, during the day, for a 29 days period. Another 4 control sheep were maintained in a neighboring pasture without $F$. humboldtiana. Skin lesions characteristic of photosensitization were observed after 11-25 days of $F$. humboldtiana grazing. Serum activities of AST and GGT, and serum levels of bilirubin were within normal ranges. At the end of the 29 days grazing $F$. humboldtiana, 2 sheep were euthanized, and 2 were withdrawn from the pastures. No gross or histologic liver lesions were observed on the 2 sheep euthanized; the other 2 sheep recovered within 17 and 20 days after the end of grazing. One mare and its foal grazed in the same pasture during 44 days. The mare that had a pigmented skin had no dermatitis, but the foal showed dermatitis on the white areas of the skin after $\mathbf{2 5}$ days of grazing. The two horses were withdrawn from the pastures after 44 days grazing, and the foal fully recovered within 15 days. These experiments indicate that $F$. humboldtiana causes primary photosensitization in domestic animals. The absence of lesions in animals ingesting the plant collected in the field and kept refrigerated suggests that $F$. humboldtiana lost toxicity after collection. The absence of lesions in the eyes of affected animal, which are characteristic of primary photosensitization caused by furocoumarins containing plants, suggests that $F$. humboldtiana contains a naphthodianthrone derivate, similar to those found in Fagopyrum esculentum and Hypericum perforatum which do not cause eye lesions.
\end{abstract}

INDEX TERMS: Primary photosensitization, Froelichia humboldtiana, Amaranthaceae, equidae, ruminants, dermatitis.

\footnotetext{
${ }^{1}$ Recebido em 29 de agosto de 2006.

Aceito para publicação em 11 de setembro de 2006.

2 Médico Veterinário, Praça Duque de Caxias 311, Tucano, BA 48790-000. E-mail: luckha@bol.com.br
}

\footnotetext{
${ }^{3}$ Centro de Saúde e Tecnologia Rural, Universidade Federal de Campina Grande (UFCG), Campus de Patos, 58700-000 Patos, Paraíba, Brasil. *Autor para correspondência: franklin.riet@pesquisador.cnpq.br

${ }^{4}$ Pós-graduando de Mestrado em Medicina Veterinária de Pequenos Ruminantes, Hospital Veterinário, CSTR, UFCG, 58700-000 Patos, PB.
} 
RESUMO.- Fotossensibilização é freqüente em eqüinos no semiárido da região Nordeste, mas jumentos, mulas, ovinos e bovinos são, também, afetados. A dermatite afeta, principalmente, áreas de pele despigmentadas e os animais se recuperam após serem retirados das pastagens. Para comprovar a etiologia da enfermidade Froelichia humboldtiana (Roem. et Schult.) Seub., coletada no campo foi administrada no mesmo dia da colheita ou após ser mantida em refrigerador por 1-4 dias, por períodos de 30 ou mais dias, ad libitum como único alimento, a 2 jumentos e um ovino branco e, como único alimento volumoso, a um eqüino branco. Esses animais não manifestaram sinais clínicos e as atividades séricas de gama-glutamiltransferase (GGT), aspartato-aminotransferase (AST) e alanino-aminotransferase (ALT) ficaram dentro dos valores normais. Em outro experimento, um ovino foi colocado a pastar diariamente, durante o dia, preso por uma corda em uma área que tinha exclusivamente $F$. humboldtiana, por um período de 26 dias. Lesões características de fotossensibilização foram observadas 4-5 dias após o início do experimento. Após cessar o consumo da planta, no $26^{\circ}$ dia, o ovino recuperou-se totalmente em 30 dias. Em outro experimento, 4 ovinos foram também colocados, presos por cordas, na mesma área. Outros 4 permaneceram como controles em uma pastagem vizinha, mas sem $F$. humboldtiana. Lesões de pele, características de fotossensibilização foram observadas após 1125 dias de consumo de $F$. humboldtiana. As atividades séricas de AST e GGT, e os níveis de bilirrubina sérica permaneceram dentro dos valores normais. No final do período de permanência em pastagens de F. humboldtiana, 2 ovinos foram abatidos e 2 foram retirados da pastagem. Os que foram abatidos não apresentaram lesões macroscópicas nem histológicas do fígado; os outros dois se reculperaram das lesões da pele 17 e 20 dias após o fim do pastejo. Uma égua e seu potro foram colocados na mesma pastagem com $F$. humboldtiana por um período de 44 dias. A égua, que não tinha áreas de pele despigmentadas não apresentou lesões, no entanto o potro desenvolveu dermatite nas áreas brancas de pele 25 dias após o início do pastejo. Após serem retirados da pastagem o potro recuperou-se totalmente em 15 dias. Estes experimentos indicam que $F$. humboldtiana causa fotossensibilização primária em animais domésticos. A ausência de lesões nos animais que ingeriram a planta após ser coletada e mantida em geladeira sugere que a planta perde sua toxicidade depois da coleta. A ausência de lesões oculares características da intoxicação por furocumarinas sugere que $F$. humboldtiana contém derivados da naftodiantrona, similares aos encontrados em Fagopyrum esculentum e Hypericum perforatum que não causam lesões oculares.

TERMOS DE INDEXAÇÃO: Fotossensibilização primária, Froelichia humboldtiana, Amaranthaceae, eqüídeos, ruminantes, dermatite.

\section{INTRODUÇÃO}

Surtos de fotossensibilização, principalmente em eqüinos, mas afetando também ovinos e bovinos têm sido relatados no semiárido desde a década de 1950. Casos de fotossensibilização em equiinos foram observados nos municípios de Casa Nova, na Bahia, Parnaíba e Campo Maior, no Piauí, e Quixadá, no Ceará. Na Bahia e no Piauí a fotossensibilização era associada à planta denominada como ervanço, identificada na época como Froelichia lanata Moq. Pelo contrário, em Quixadá, os produto- res mencionaram que a planta engorda o gado e que é boa para dar leite (Carlos Tokarnia, UFRRJ, 2003, comunicação pessoal).

Diversos surtos de fotossensibilização em eqüinos, e alguns casos em bovinos foram descritos no Rio Grande do Norte, na região do Seridó, onde alguns produtores mencionaram que a doença era causada por Croton hirtus (Riet-Correa et al. 2003). Tentativas de reprodução experimental da enfermidade administrando $C$. hirtus, como único alimento, a um jumento e um ovino, durante 30 dias, resultaram negativos (Riet-Correa et al. 2003, dados não publicados).

Recentemente, casos de fotossensibilização foram estudados no semi-árido do Rio Grande do Norte na microrregião de Mossoró. Em 17 propriedades havia 512 bovinos, 62 equïinos e 210 ovinos, sendo que $5,7 \%$ dos bovinos, $13 \%$ dos eqüinos e $0,3 \%$ dos ovinos apresentavam fotossensibilização. Em todas as propriedades havia Froelicha humboldtiana (Roem. et Schult.) Seub. nas áreas onde adoeciam os animais e os autores sugerem que a fotossensibilização é causada por essa planta. Produtores mencionaram a ocorrência da doença também em caprinos e asininos (Macedo et al. 2005).

Surtos de fotossensibilizão afetando principalmente equiinos, mas também muares, asininos, ovinos e bovinos são observados no semiárido da Paraíba, tanto no Agreste quanto no Sertão. A doença, conhecida pelos produtores como "sarna", ocorre durante o período de chuvas, principalmente no final do mesmo, de março a maio, em propriedades em que as pastagens estão invadidas por grandes quantidades de Froelichia humboldtiana (Fig.1), conhecida popularmente como ervanço. Em geral as lesões de fotossensibilização nos equíideos afetam as partes despigmentadas da pele (Fig.2) e os animais se reculperam em poucos dias após serem retirados das pastagens. Alguns animais podem apresentar lesões em áreas pigmentadas e, em outros casos, as lesões demoram a regredir, mesmo após a retirada dos animais das áreas com ervanço, em consequiência do prurido que faz com que os animais se cocem seguidamente causando lesões secundárias. Em ovinos as regiões anatômicas mais afetadas são a face e as orelhas, principalmente em animais de pelagem branca. Em bovinos os animais da raça Holandesa são mais afetados, apresentando lesões nas áreas despigmentadas. Em nenhuma dessas espécies se registram mortes e os animais se recuperam após serem retirados das pastagens onde ocorre a planta.

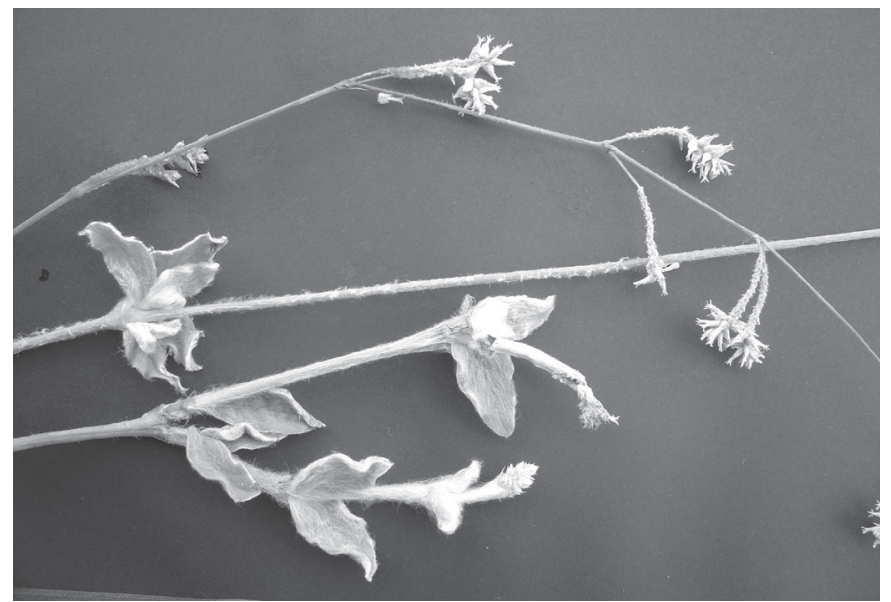

Fig.1. Froelichia humboldtiana, no município de Patos, Paraíba. 


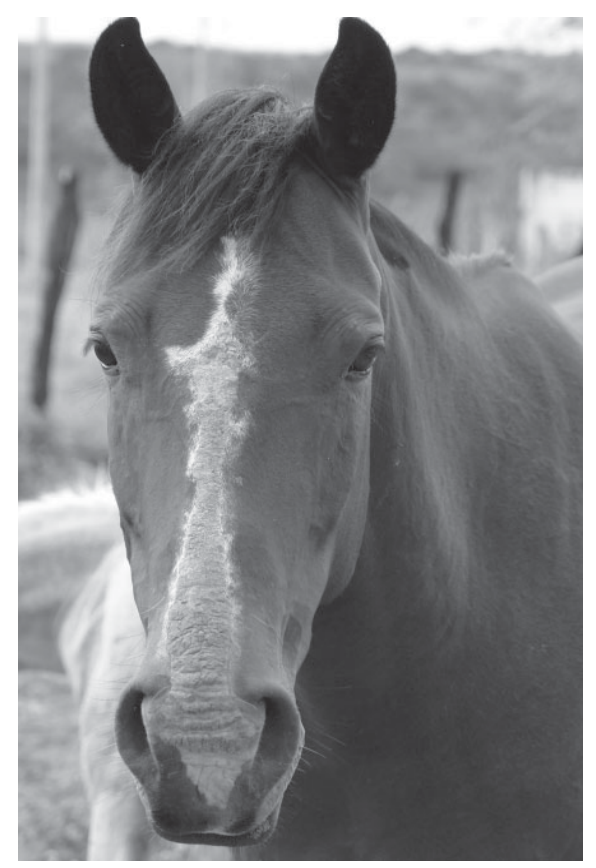

Fig.2. Eqüino com fotossensibilização, caracterizada por dermatite de área despigmentada na região frontal da cabeça.

Na Bahia, na região do município de Tucano, a doença é muito conhecida afetando principalmente ovinos de pele despigmentada. Os ovinos são a espécie animal mais criada na região e os produtores sabem que os animais de pele branca são afetados pela enfermidade. Os produtores, em geral, não têm eqüinos de pele clara, pois sabem que certamente vão apresentar fotossensibilização se colocados em pasto com ervanço. Os cavalos com pelagem branca ou com áreas despigmentadas têm pouco valor comercial, sendo conhecidos, pelos produtores, como animal que dá "sarna” (Luciano Pimentel 2006, dados não publicados).

Este trabalho teve como objetivo determinar a toxicidade de F. humboldtiana como causa de fotossensibilização no semiárido do Nordeste do Brasil. Para isso, foram realizados experimentos administrando $F$. humboldtiana coletada na microrregião de Patos, Paraíba, e experimentos com pastejo de ovinos e eqüinos em áreas invadidas pela planta no município de Tucano, Bahia, onde, no ano anterior, tinha ocorrido um surto de fotossensibilização em ovinos. Adicionalmente, foram realizados exames bioquímicos e necropsias dos ovinos intoxicados experimentalmente para determinar se a fotossensibilização é primária ou secundária.

\section{MATERIAL E MÉTODOS}

Administração de Froelichia humboldtiana a animais experimentais

F. humboldtiana, coletada uma ou duas vezes por semana, foi administrada a um ovino branco, uma jumenta de pelagem clara, lactante, um jumento lactente e um cavalo totalmente branco. A planta era administrada imediatamente após a colheita ou após ser mantida em câmara fria a aproximadamente $5^{\circ} \mathrm{C}$ por 3-4 dias.

O ovino branco, cruza da raça Santa Inês e pesando $15 \mathrm{~kg}$, ingeriu a planta à vontade, como único alimento, durante 15 dias, entre os dias 8 e 22 de março de 2004. Posteriormente, a planta foi administrada novamente, nas mesmas condições, por 30 dias, de 23 de abril até
23 de maio de 2004. Diariamente o animal era submetido ao sol por períodos de pelo menos 2 horas. A atividade sérica de gamaglutamiltransferase (GGT), alanino-aminotransferase (ALT) e aspartatoaminotransferasa (AST) do ovino experimental e de dois ovinos controles foram determinados no início do experimento e ao final de cada período experimental.

No dia 23.3.04 foi iniciado um experimento com uma jumenta da raça Jumento Nordestino e seu filho lactente de aproximadamente 3 meses de idade. A planta coletada foi administrada à vontade aos dois animais, por 30 dias. Os níveis séricos de AST, ALT e GGT dos dois animais e de um jumento controle foram determinados no início e final do experimento.

A planta foi administrada, também, a um cavalo totalmente branco, de 18 meses de idade pesando aproximadamente $250 \mathrm{~kg}$, por 30 dias, de 11 de maio até 9 de junho de 2005. Durante o dia o animal recebia a planta à vontade e no final da tarde recebia um suplemento de $0,5-1 \mathrm{~kg}$ de concentrado. No início e no final do experimento foi determinada a atividade sérica de AST, ALT e GGT e as concentrações séricas de proteína total, albumina e globulina.

Todos os exames bioquímicos foram realizados em um laboratório privado da cidade de Patos (PARA EXAME, Patos, Paraíba).

\section{Reprodução de fotossensibilização em ovinos pastando em áreas} invadidas por Froelichia humboldtiana

Estes experimentos foram desenvolvidos no município de Tucano, Bahia, em uma fazenda onde tinha ocorrido um surto de fotossensibilização em ovinos no ano 2005, que afetou um rebanho de 25 ovinos deslanados cruzas, que tinham sido comprados recentemente e colocados em uma área invadida por $F$. humboldtiana. Quatro desses ovinos, que tinham pelagem branca, apresentaram lesões de fotossensibilização nas orelhas, ao redor dos olhos, focinho e parte superior do pescoço e cernelha. Os animais recuperaram-se após serem retirados do pasto e tratados com um medicamento para mí́asis. Nesses mesmos pastos, em anos anteriores, a proprietária tinha observado lesões de dermatite em uma vaca mestiça de Holandesa que apresentava lesões no úbere e partes despigmentadas da pele durante a época de chuvas, sempre que era colocada no pasto invadido por $F$. humboldtiana.

Em 2006, quando foi realizado o experimento, F. humboldtiana começou a brotar em grande quantidade, como pastagem dominante no início das chuvas (meados de março), com intensa floração e desenvolvimento do pendão em meados de abril. Nesse momento a pastagem era praticamente só de ervanço; somente no final de maio e início de junho começaram a aparecer outras plantas invasoras.

Em um primeiro experimento um ovino branco (Ovino 1), cruza da raça Santa Inês, foi colocado, diariamente, preso por uma corda de 6 metros de comprimento, em diversos locais do campo mencionado anteriormente, no período de 22 de abril até 17 de maio de 2006 (26 dias). Na área onde $o$ animal pastejava foram arrancadas manualmente outras plantas de forma que a única planta ingerida fosse $F$. humboldtiana. $\mathrm{O}$ animal era deixado na área durante o dia e a noite era colocado em um local fechado sem acesso a outro alimento.

Em um segundo experimento foram utilizados 8 ovinos deslanados, cruzas da raça Santa Inês, que foram divididos em dois grupos de 4 animais. Cada grupo possuía animais de idade semelhante: 3 de até 6 meses e um adulto. No Grupo 1 havia 3 ovinos com pelagem branca e no Grupo 2 um ovino de pelagem branca. O Grupo 1 (Ovinos 2 a 5) foi colocado a pastar da mesma forma que o ovino anterior, presos por cordas em diversos locais da área onde $F$. humboldtiana era a única forragem disponível (Fig.3). Os ovinos do Grupo 2 (Ovinos 6 a 9) foram mantidos numa área livre da planta juntos ao restante do rebanho (28 animais) em pastagens onde havia gramíneas nativas, Cynodon spp e diversas espécies de plantas invasoras, mas não havia $F$. humboldtiana. No início do experimento em 


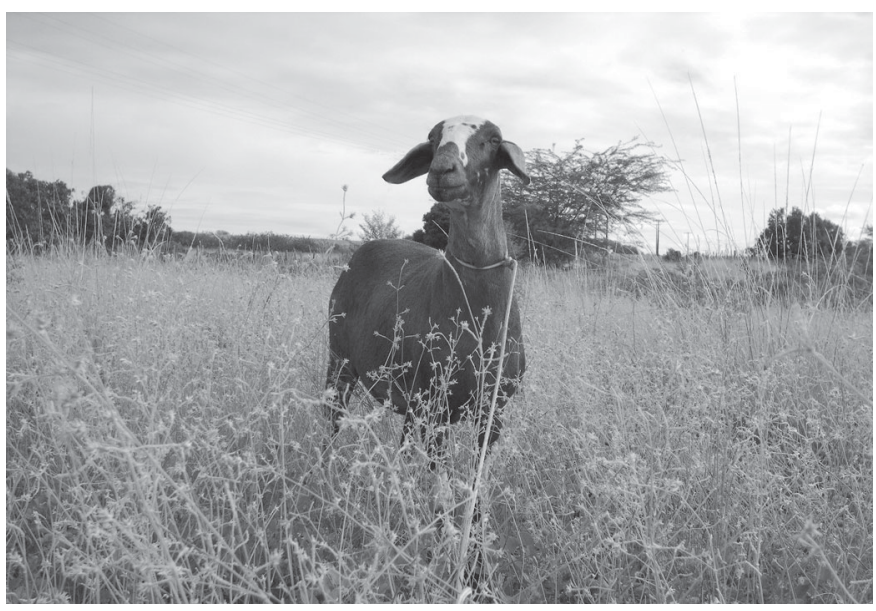

Fig.3. Ovino 5, no momento do início do experimento. Observa-se que na área de pastagem a que ele tinha acesso havia unicamente Froelichia humboldtiana.

23.5.2006 e semanalmente até o dia 20.6.2006 foram coletadas amostras de sangue dos 8 ovinos que eram enviadas a um laboratório privado (DELTA-Laboratório de Apoio), na cidade de Tucano, para determinação da atividade sérica GGT e AST e níveis de bilirrubina total indireta e conjugada. Dois animais do grupo experimental (Ovinos 3 e 4 ) foram abatidos no final do experimento, em 21.6.2006, e necropsiados. Materiais dos órgãos das cavidades abdominal e torácica, sistema nervoso central e pele com lesões de fotossensibilização foram fixados em formalina a $10 \%$, incluídos em parafina, cortados em secções de $5 \mathrm{~mm}$ e corados por hematoxilinaeosina para estudo histológico. Os restantes animais (Ovinos 2, 5, 6, 7, 8 e 9) foram observados até o desaparecimento das lesões dos que tinham ingerido $F$. humboldtiana. Duas semanas após o final da ingestão de $F$. humboldtiana foram coletadas amostras de sangue para exame bioquímico.

Dois eqüinos, uma égua lactante, de pele pigmentada, e seu potro, com áreas de pelagem branca nos membros e cabeça, foram colocados a pastar, entre os dias 23.5.2006 e 1.8.2006, na pastagem onde estavam as ovelhas, onde havia uma grande quantidade de $F$. humboldtiana, que era a planta dominante. Durante esse período os animais permaneceram dia e noite soltos na pastagem.

\section{Identificação botânica da planta}

Amostras da planta coletada durante os experimentos foram enviadas para o Professor Odací F. de Oliveira, Universidade Federal Rural do Semi-árido, que a identificou como Froelichia humboldtiana (Roem. et Schult.) Seub., da família Amaranthaceae.

\section{RESULTADOS}

\section{Administração de Froelichia humboldtiana a animais experi- mentais}

Nenhum dos animais experimentais (dois jumentos, um cavalo e um ovino) apresentou lesões de pele nem outros sinais clínicos. A atividade sérica de GGT, ALT e AST de todos os animais e os níveis de proteína total, albumina e globulina do cavalo, estavam dentro dos valores normais, tanto no início quanto no final do experimento.

O total de planta ingerida pelo ovino durante o primeiro período de 15 dias foi de $32,305 \mathrm{~kg}$, com uma média diária de 2,15 $\mathrm{kg}$. O consumo de planta durante o segundo período, de 30 dias, não foi registrado. A jumenta e o jumento que ingeriram a planta juntos durante 30 dias consumiram um total de $447,22 \mathrm{~kg}$ de plan- ta. $O$ cavalo ingeriu $234,4 \mathrm{~kg}$ de planta, com uma média de 7,8 kg por dia.

\section{Reprodução de fotossensibilização em ovinos pastando em áreas invadidas por Froelichia humboldtiana}

No experimento inicial, com um ovino (Ovino 1), este apresentou dermatite na parte externa das orelhas 4-5 dias após o início do experimento. Posteriormente, as lesões afetaram, também, a pele ao redor dos olhos, focinho, rima labial, porção dorsal do pescoço e região dorsal do tórax (cernelha). Essas lesões inicialmente discretas foram se agravando, até que no $22^{\circ}$ dia de permanência na pastagem eram severas com edema da pele, formação de crostas e alopecia (Fig.4). Nas orelhas havia um exsudato seroso com estrias de sangue. Nesse dia o animal foi retirado da pastagem e as lesões começaram a regredir. A regressão completa aconteceu 30 dias após o final do consumo da planta, sem que tenha sido feito nenhum tratamento.

No experimento em que foram colocados 4 ovinos na pastagem com $F$. humboltiana, os Ovinos 2, 3 e 4 apresentaram lesões de pele 10 a 11 dias após serem introduzidos na pastagem, enquanto que o Ovino 5, o único que era pigmentado, somente apresentou lesões no $25^{\circ}$ dia. Todos os animais apresentaram lesões na parte externa das orelhas, sendo que no Ovino 5 essas lesões foram discretas. Os Ovinos 2, 3 e 4 apresentaram também lesões ao redor dos olhos e focinho. Nos Ovinos 3 e 4 as lesões afetavam também a rima labial e no Ovino 3 havia dermatite da porção dorsal do pescoço (Fig.5). Após serem retirados da pastagem, no $29^{\circ}$ dia, os Ovinos 2 e 5 recuperaram-se totalmente em 17 e 20 dias, respectivamente. Os Ovinos 3 e 4 foram abatidos no $30^{\circ}$ dia e necropsiados. Os valores da bioquímica sanguínea dos 8 animais experimentais são apresentados nos Quadros 1 a 5. No estudo histológico dos Ovinos 3 e 4 não foram observadas lesões significativas no fígado, rim, baço, gânglios linfáticos, pulmão, coração e sistema nervoso central. Na pele havia dermatite necrosupurativa localmente extensiva, aguda, acentuada, caracterizada por microabscessos intracorneais com restos celulares

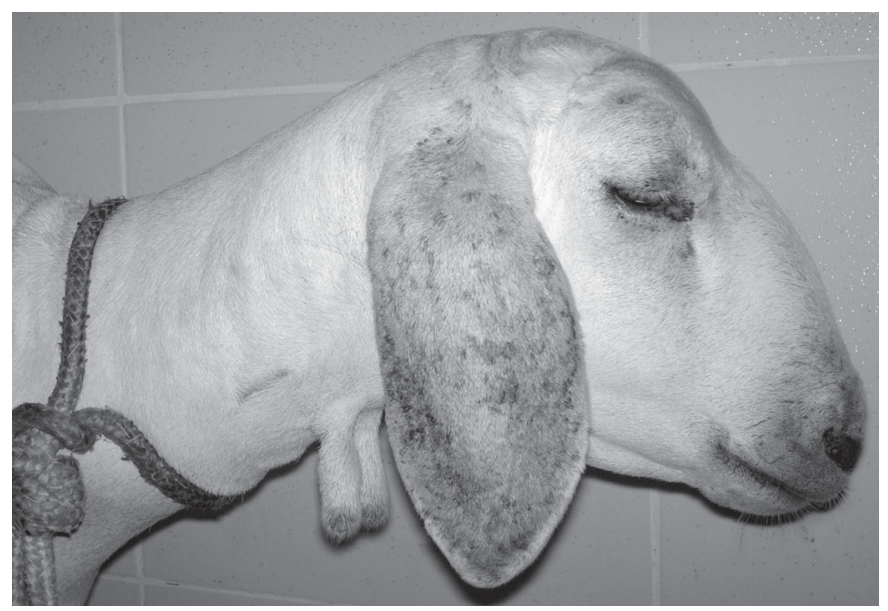

Fig.4. Ovino 1, após 22 dias de introduzido na pastagem e consumo exclusivo de Froelichia humboldtiana. Observam-se lesões de fotossensibilização caracterizadas por dermatite com alopecia, exsudato e formação de crostas na pele de orelhas, focinho, lábios e ao redor dos olhos. Há edema nas orelhas e ao redor dos olhos. 


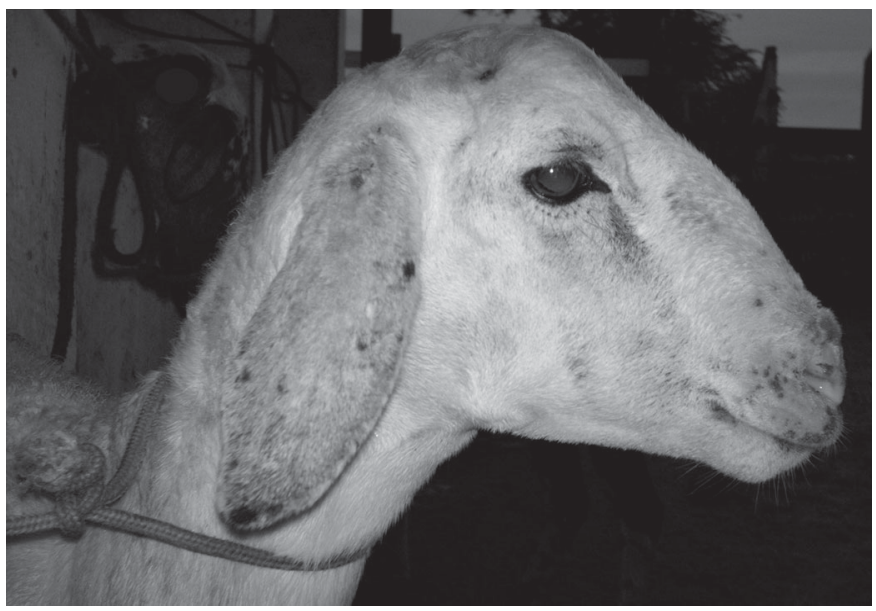

Fig.5. Ovino 4, após 29 dias de consumo exclusivo de Froelichia humboldtiana. Observam-se lesões de fotossensibilização caracterizadas por dermatite com alopecia, exsudato e formação de crostas na pele das orelhas, focinho, lábios, pele ao redor dos olhos e porção dorsal do pescoço.

necróticos, infiltrado subcorneal de neutrófilos, paraqueratose, acantose, hiperplasia pseudoepiteliomatosa, edema intercelular (espongiose) e vacuolização de queratinócitos. Em algumas áreas havia crostras formadas por neutrófilos necróticos e colônias bacterianas. A derme superficial apresentava-se distendida por edema, com microabscessos e infiltrado perivascular predominantemente de neutrófilos, além de alguns eosinófilos, linfócitos e plasmócitos. Havia capilares dilatados e congestos.

A égua que foi colocada a pastar, solta, junto com o seu potro, na mesma pastagem onde foi realizado o experimento, não apresentou sinais, pois não tinha áreas da pele despigmen-tadas. 0 potro apresentou lesões de fotossensibilização, observadas a partir do $25^{\circ}$ dia de pastoreio, afetando as partes brancas da pele: a região frontal da cabeça e a região distal dos 4 membros. Essas lesões também regrediram em 12-15 dias após os equiinos serem retirados das pastagens.

\section{DISCUSSÃO E CONCLUSÕES}

A reprodução experimental de fotossensibilização nos 5 ovinos, em áreas onde havia exclusivamente Froelichia humboldtiana, e a ausência de lesões nos animais pastando em áreas sem a planta comprovam que a doença é causada por essa planta.

Desconhecemos a causa da falha em reproduzir a doença em

Quadro 1. Valores de GGT (U/L) em 4 ovinos pastando em áreas invadidas por Froelichia humboldtiana (Ovinos 2 a 5) e 4 ovinos do grupo controle (Ovinos 6 a 9)

\begin{tabular}{ccccccc}
\hline $\begin{array}{c}\text { Ovino } \\
\mathrm{n}^{\circ}\end{array}$ & 0 dia & $7^{\circ}$ dia & $1^{\circ}$ dia & $21^{\circ}$ dia & $29^{\circ}$ dia & $\begin{array}{c}15 \text { dias após } \\
\text { o pastejo }\end{array}$ \\
\hline 2 & 92 & 83 & 80 & 89 & 82 & 83 \\
3 & 77 & 88 & 99 & 86 & 89 & $\mathrm{~A}^{\mathrm{a}}$ \\
4 & 116 & 94 & 99 & 98 & 90 & $\mathrm{~A}$ \\
5 & 68 & 59 & 61 & 62 & 59 & 56 \\
6 & 70 & 68 & 123 & 62 & 60 & 59 \\
7 & 139 & 124 & 121 & 114 & 97 & 352 \\
8 & 84 & 92 & 91 & 83 & 81 & 81 \\
9 & 68 & 66 & 69 & 68 & 71 & 80
\end{tabular}

a Animal abatido no final do consumo da planta.
Quadro 2. Valores de AST (U/L) em 4 ovinos pastando em áreas invadidas por Froelichia humboldtiana (Ovinos 2 a 5) e 4 ovinos do grupo controle (Ovinos 6 a 9)

\begin{tabular}{ccccccc}
\hline $\begin{array}{c}\text { Ovino } \\
\mathrm{n}^{\mathrm{o}}\end{array}$ & 0 dia & $7^{\circ}$ dia & $14^{\circ}$ dia & $21^{\circ}$ dia & $29^{\circ}$ dia & $\begin{array}{c}15 \text { dias após } \\
\text { o pastejo }\end{array}$ \\
\hline 2 & 167 & 145 & 148 & 147 & 152 & 187 \\
3 & 188 & 153 & 143 & 147 & 135 & $\mathrm{~A}^{\mathrm{a}}$ \\
4 & 197 & 210 & 151 & 143 & 145 & $\mathrm{~A}$ \\
5 & 137 & 116 & 179 & 146 & 107 & 107 \\
6 & 118 & 123 & 121 & 122 & 118 & 109 \\
7 & 109 & 100 & 115 & 133 & 119 & 1046 \\
8 & 128 & 128 & 118 & 111 & 118 & 128 \\
9 & 150 & 148 & 176 & 154 & 135 & 125
\end{tabular}

a Animal abatido no final do consumo da planta.

Quadro 3. Valores de bilirrubina total (mg/dL) em 4 ovinos pastando em áreas invadidas por Froelichia humboldtiana (Ovinos 2 a 5) e 4 ovinos do grupo controle (Ovinos 6 a 9)

\begin{tabular}{ccccccc}
\hline $\begin{array}{c}\text { Ovino } \\
\mathrm{n}^{\circ}\end{array}$ & 0 dia & $7^{\circ}$ dia & $1^{\circ}$ dia & $2^{\circ}$ dia & $29^{\circ}$ dia & $\begin{array}{c}15 \text { dias após } \\
\text { o pastejo }\end{array}$ \\
\hline 2 & 0.1 & 0.1 & 0.1 & 0.2 & 0.3 & 0.3 \\
3 & 0.2 & 0.4 & 0.8 & 0.3 & 0.8 & $\mathrm{~A}^{\mathrm{a}}$ \\
4 & 2.2 & 0.6 & 0.5 & 0.5 & 0.4 & $\mathrm{~A}$ \\
5 & 0.2 & 0.1 & 0.1 & 0.1 & 0.5 & 0.5 \\
6 & 0.1 & 0.1 & 0.1 & 0.1 & 0.1 & 0.3 \\
7 & 0.1 & 0.1 & 0.1 & 0.4 & 0.1 & 1.1 \\
8 & 0.1 & 0.2 & 0.1 & 0.2 & 0.1 & 0.6 \\
9 & 0.1 & 0.1 & 0.3 & 0.1 & 0.2 & 0.4
\end{tabular}

animal abatido no final do consumo da planta

Quadro 4. Valores de bilirrubina não conjugada (mg/dL) em 4 ovinos pastando em áreas invadidas por Froelichia humboldtiana (Ovinos 2 a 5) e 4 ovinos do grupo controle (Ovinos 6 a 9)

\begin{tabular}{ccccccc}
\hline $\begin{array}{c}\text { Ovino } \\
\mathrm{n}^{\circ}\end{array}$ & 0 dia & $7^{\circ}$ dia & $14^{\circ}$ dia & $21^{\circ}$ dia & $29^{\circ}$ dia & $\begin{array}{c}15 \text { dias após } \\
\text { o pastejo }\end{array}$ \\
\hline 2 & 0.2 & 0.2 & 0.2 & 0.2 & $\mathrm{ND}^{\mathrm{a}}$ & 0.2 \\
3 & 0.2 & 0.2 & 0.3 & 0.2 & $\mathrm{ND}$ & $\mathrm{A}^{\mathrm{b}}$ \\
4 & 0.0 & 0.0 & 0.0 & 0.0 & $\mathrm{ND}$ & $\mathrm{A}$ \\
5 & 0.3 & 0.3 & 0.3 & 0.3 & $\mathrm{ND}$ & 0.4 \\
6 & 0.2 & 0.2 & $\mathrm{ND}$ & 0.3 & $\mathrm{ND}$ & 0.2 \\
7 & 0.2 & 0.2 & 0.2 & 0.4 & $\mathrm{ND}$ & 0.6 \\
8 & 0.2 & 0.2 & 0.2 & 0.4 & $\mathrm{ND}$ & 0.3 \\
9 & 0.2 & 0.2 & 0.2 & 0.2 & $\mathrm{ND}$ & 0.2
\end{tabular}

a Não determinado, ${ }^{\mathrm{b}}$ Animal abatido no final do consumo da planta.

um ovino, dois asininos e um eqüino que ingeriram a planta, como único alimento no caso dos asininos e do ovino e como alimento principal no caso do equiino, coletada em áreas próximas ao lugar onde foi realizado o experimento. Como a planta era coletada uma ou duas vezes por semana e conservada na câmara fria, uma possibilidade é que a mesma perca a toxicidade após ser arrancada. Dentre as plantas que causam fotossensibilização primária, Hypericum perforatum contém como princípio ativo uma substância derivada da naftodiantrona (hipericina) que após a fenação perde aproximadamente $80 \%$ de sua toxicidade (Munro 2006). Outro fato é que a planta foi coletada em locais onde não havia animais, portanto há a possibilidade de que no local e mo- 
Quadro 5. Valores de bilirrubina conjugada (mg/dL) em 4 ovinos pastando em áreas invadidas por Froelichia humboldtiana (Ovinos 2 a 5) e 4 ovinos do grupo controle (Ovinos 6 a 9)

\begin{tabular}{ccccccc}
\hline $\begin{array}{c}\text { Ovino } \\
\mathrm{n}^{\circ}\end{array}$ & 0 dia & $7^{\circ}$ dia & $1^{\circ}{ }^{\circ}$ dia & $2^{\circ}$ dia & $29^{\circ}$ dia & $\begin{array}{c}15 \text { dias após } \\
\text { o pastejo }\end{array}$ \\
\hline 2 & 0.0 & 0.0 & 0.0 & 0.0 & $\mathrm{ND}^{\mathrm{a}}$ & 0.1 \\
3 & 0.1 & 0.0 & 0.0 & 0.0 & $\mathrm{ND}$ & $\mathrm{A}^{\mathrm{b}}$ \\
4 & 0.8 & 0.5 & 0.4 & 0.3 & $\mathrm{ND}$ & $\mathrm{A}$ \\
5 & 0.0 & 0.0 & 0.0 & 0.0 & $\mathrm{ND}$ & 0.1 \\
6 & 0.0 & 0.0 & $\mathrm{ND}$ & 0.0 & $\mathrm{ND}$ & 0.1 \\
7 & 0.0 & 0.0 & 0.0 & 0.0 & $\mathrm{ND}$ & 0.5 \\
8 & 0.0 & 0.0 & 0.0 & 0.0 & $\mathrm{ND}$ & 0.3 \\
9 & 0.0 & 0.0 & 0.0 & 0.0 & $\mathrm{ND}$ & 0.2 \\
\hline
\end{tabular}

a Não determinado, ${ }^{\text {b }}$ Animal abatido no final do consumo da planta.

mento em que foi coletada não apresentasse toxicidade. Uma terceira possibilidade é que a planta cause fotossensibilização por contato e que, ao ser administrada por via oral, não cause lesões. Esta última é menos provável por que em alguns casos experimentais ocorreram lesões no dorso e região dorsal do pescoço, áreas que dificilmente tem contato com a planta. No entanto devemos considerar que algumas plantas que causam fotossensibilização primária, como Ammi majus, as lesões de pele são devidas tanto à ingestão quanto ao contato (Méndez et al. 1991), pelo que não se pode descartar que $F$. humboldtiana cause, também, fotossensibilização primária por contato.

Os resultados dos exames bioquímicos semanais dos ovinos pastando na área invadida por $F$. humboldtiana, que apresentaram sinais de fotossensibilização, se mantiveram dentro dos valores normais durante todo o período experimental e não diferiram dos animais do grupo controle, exceto do Ovino 7, do grupo controle, que apresentou valores aumentados de GGT durante todo o experimento e de AST e bilirrubina aumentadas na última coleta. Esses resultados e a ausência de lesões macroscópicas e histológicas nos animais abatidos no final do experimento indicam que a fotossensibilização é primária. Este mecanismo sugerem também os dados epidemiológicos e clínicos dos casos espontâneos, já que não se registram mortes de animais e as lesões de pele, que são menos severas que as causadas por plantas que causam fotossensibilização secundária, regridem rapidamente quando os animais são retirados das pastagens invadidas pela planta. Além disso, não são observados outros sinais clínicos de insuficiência hepática tais como edemas de declive, icterícia, encefalopatia hepática, hemorragias e diarréia ou fezes ressecadas com muco e/ou sangue.

Um fato evidente nos históricos da doença nas diferentes regiões do Nordeste é que os eqüinos são mais afetados que as demais espécies. Isto pode ser devido a que $F$. humboldtiana seja mais palatável para equiinos do que para outras espécies ou a que os eqüinos são mais sensíveis ao princípio ativo da planta, que é desconhecido. Esta última possibilidade parece ser pouco provável, já que o potro com áreas de pele branca que foi introduzido no mesmo momento que os ovinos, demorou mais tempo que estes em apresentar fotossensibilização e a égua que não tinha áreas de pele branca, não apresentou lesões. No entanto, esses resultados devem ser interpretados com cuidado, já que os cavalos estavam soltos na pastagem e certamente ingeriam outras plantas que estavam misturadas a $F$. humboldtiana; além disso, o potro ingeria leite materno.

No Brasil, a única planta que causa surtos de fotossensibilização primária é Ammi majus (Méndez et al. 1991), que contém compostos furocumarínicos com atividade fotossensibilizante (Cheeke 1985). Outras plantas que causam fotossensibilização primária são Fagopyrum esculentum, que contém uma quinona conjugada, derivada da naftodiantrona, denominada fagopirina e Hypericum perforatum que contém uma substância similar à fagopirina denominada hipericina (Cheeke 1985). A diferença nos animais intoxicados por furocumarinas, com os intoxicados por naftodiantronas é que nos primeiros ocorrem lesões oculares (edema da córnea, ceratoconjuntivite e cegueira) o que não ocorre nas intoxicações por naftodiantronas (Yager \& Scott 1993). A ausência de lesões oculares em casos espontâneos e experimentais de intoxicação por $F$. humboldtiana e a perda da toxicidade, mencionada anteriormente, sugere que esta planta contenha, também, naftodiantronas ou substâncias semelhantes.

Até o momento há pouca informação disponível para o controle de $F$. humboldtiana que é uma planta palatável muito invasora, encontrada como dominante em muitas pastagens degradadas do semi-árido. Como a equiina é a espécie mais afetada é importante não colocar cavalos, principalmente aqueles com área de pele branca, em pastagens invadidas por F. humboldtiana, entre os meses de abril e junho. Em casos de constatação de sinais clínicos é necessário retirar os animais afetados das pastagens colocando-os em um lugar com sombra até o desaparecimento das lesões. Naqueles animais que apresentam prurido devem procurar-se formas de proteger as áreas afetadas para evitar que os animais se cocem causando-se lesões secundárias. Com base na ausência de sinais clínicos em animais que ingeriram a planta depois de coletada e conservada em geladeira, poderia recomendar-se a fenação de $F$. humboldtiana para a sua posterior utilização como forragem.

Agradecimentos.- Este trabalho foi financiado pelo Programa de Apoio a Núcleos de Excelência (PRONEX), Proc.no.001/04, CNPq, FAPESQ, MCT, e pelo programa Institutos do Milênio, Proc.no.420012/2005-2, CNPq. Os autores agradecem ao Professor Odací F. de Oliveira, Professor aposentado da Universidade Federal Rural do Semi-árido, pela identificação botânica da planta.

\section{REFERÊNCIAS}

Cheeke P.R. 1998. Natural Toxicants in Feeds, Forages and Poisonous Plants. 2nd ed. Interstates Publishers, Danvelle, Illinois. 479p.

Macedo M.C., Bezerra M.B. \& Soto-Blanco B. 2006. Fotossensibilização em animais de produção na região semi-árida do Rio Grande do Norte. Arqs Inst. Biológico, São Paulo, 73(2):251-254.

Méndez M.C., Riet-Correa F., Schild A.L., Ferreira J.L. \& Pimentel M. 1991. Fotossensibilização em bovinos causada por Ammi majus (Umbelliferae) no Rio Grande do Sul. Pesq. Vet. Bras. 11:17-19.

Munro D.B. 2006. Canadian Poisonous Plants Information System. Notes on poisoning: Hypericum perforatum. http://sis.agr.gc.ca/pls/pp/poison?p_x=px. Consultado em 12.8.2006.

Riet-Correa F., Tabosa I.M., Azevedo E.O., Medeiros R.M., Simões S.V.D., Dantas A. F., Alves C.J., Nobre V.M.T., Athayde A.C., Gomes A.A. \& Lima E.F. 2003. Doenças dos ruminantes e eqüinos no semi-árido da Paraíba. Semi-Árido em Foco, Patos, 1(1):2-86.

Yager J.A. \& Scott D.W. The skin and appendages, p.531-738. In: Jubb K.V.F,, Kennedy P.C. \& Palmer N. (ed.), Pathology of Domestic Animals, Vol.1. 4th ed. Academic Press, San Diego. 